\title{
DIFFERENCES BETWEEN BEGINNING AND ADVANCED STUDENTS USING SPECIFIC ANALOGICAL STIMULI DURING DESIGN-BY-ANALOGY
}

\author{
Xu, Jiang; \\ Lu, Han; \\ Jiang, Yu \\ College of Design and Innovation, Tongji University
}

\begin{abstract}
Studies reported the effects of different types and different levels of abstraction of analogical stimuli on designers. However, specific, single visual analogical stimuli on the effects of designers have not been reported. We define this type of stimuli as specific analogical stimuli. We used the extended linkography method to analyze the facilitating and limiting effects of specific analogical stimuli and free association analogical stimuli (nonspecific analogical stimuli) on the students' creativity at different design levels. The results showed that: (1) Advanced students focused on exploring the depth of the design problem while beginning students tended to explore the breadth of the design problem. (2) Nonspecific analogical stimuli enhanced the creativity of beginning students. However, its impact on advanced students is less pronounced. (3) The specific analogical stimuli attract the students into design fixation. Furthermore, it has a more pronounced effect on advanced students. These results illustrate the differences in the effects of specific analogy stimuli on the students at different design levels. It clarifies the use of analogical stimuli in design and the teaching of analogical design methods in design education.
\end{abstract}

Keywords: Specific analogical stimuli, Extended linkography, Creativity, Design methods, Design process

Contact:

Lu, Han

Tongji University

College of Design and Innovation

China, People's Republic of

luhanniye@qq.com

Cite this article: Xu, J., Lu, H., Jiang, Y. (2021) 'Differences between Beginning and Advanced Students Using Specific Analogical Stimuli During Design-by-Analogy', in Proceedings of the International Conference on Engineering Design (ICED21), Gothenburg, Sweden, 16-20 August 2021. DOI:10.1017/pds.2021.127 


\section{INTRODUCTION}

Analogy is a process of association between situations from the source domain to the target domain achieved by establishing relationships (Gentner, 1988; Blanchette and Dunbar, 2000). Analogical thinking is widely used in the design domains such as engineer design (Al-Obaidi and Pitts, 1995; Ngo et al., 2014), product design (Appleton and Short, 2008; O'Rourke and Seepersad, 2015), design education (Chou and Shu, 2015), bioinspired design (Helms and Goel, 2014; Fu et al., 2014), and cognitive psychology (Paletz et al., 2013). On the one hand, analogy motivates designers, engineers, and scientists to obtain problem-solving strategies (Keshwani and Chakrabarti, 2016; Casakin and Goldschmidt, 1999). On the other hand, analogical thinking has some negative effects, such as design fixation. (Chan et al., 2011; Moreno et al., 2016).

\subsection{Analogical sources}

Analogy is an ideation strategy in design, mapping the solution and process of a system (source domain) to an objective system (objective domain) (Clement and Gentner, 1991). The researchers classified the analogical sources according to their different analogical distances. The analogical sources are categorized into between-domain sources and within-domain sources (Casakin, 2004; Christensen and Schunn, 2007). A between-domain source indicates that the analogical source is from a completely different area to the design problem, whereas a within-domain source indicates that the analogical source is from the same area of the design problem. Between-domain and within-domain analogical stimuli affect the design quality differently. Studies suggest that within-domain sources will allow designers to achieve better design performance (Howard et al., 2011; Chan and Schunn, 2014). However, some studies observed negative effects of within-domain sources and recommended using between-domain sources (Christensen and Schunn, 2007). Furthermore, other studies found that between-domain sources allow designers to generate more novel ideas and have stronger design fixation (Jansson and Smith, 1991; Cardoso and Badke-Schaub, 2009). We used between-domain analogical sources in this study to stimulate students to generate more novel ideas.

\subsection{Effects of analogical stimuli on design}

Many previous studies indicate that the use of analogy in design improves the quality of design solutions (Casakin and Goldschmidt, 1999, 2000). Studies also found that analogical stimuli led to some negative effects, such as design fixation. (Jansson and Smith, 1991; Purcell and Gero, 1996). Design fixation is defined as a phenomenon obtained using familiar knowledge, ignoring multiple strategies or limiting creativity and results of design solutions. (Jansson and Smith, 1991; Moreno, 2016). Perttula and Sipilä (2007) showed that common design example also increases fixation than novel ones. In analogical reasoning during idea generation, Cao et al. (2018) found that advanced students fall into low-level design fixation, while beginning students move into high-level design fixation. These research findings show that analogical stimuli have dual effects on design.

\subsection{Linkography and extended linkography}

Linkography was proposed by Goldschmidt (1990). The designers' concepts and intentions are both known as design moves in Linkography. Researchers decide the relationships between every two moves and then form links based on the design intention and semantic relevance. Linkography is effective in accessing both individual and group designers' protocol. Goldschmidt (2001) introduced linkography to evaluate the protocol of individual designers. Van der Lug (2000) used linkography to study the design groups' discrepancy between brainstorming and brain sketching activities. The quantitative study of linkography is promising (El-Khouly and Penn, 2014). Kan and Gero (2005) introduced entropy from Shannon's information theory into linkography calculation. Kan and Gero (2008) analyzed the design process separately in the face-to-face and NetMeeting session by introducing the link nodes into the X-Y plane. Cai et al. (2010) proposed a method known as extended linkography. This method extends the linkography with the concept of lateral transformations (LT) and vertical transformations (VT) proposed by De Bono (1990).

\subsection{Evaluation of creativity and degree of fixation}

Studies have investigated the evaluation of creativity and the degree of design fixation. Goldschmidt and Smolkov (2006) used an expert scoring method to evaluate the originality, practicality, and quality 
of design solutions. However, this subjective evaluation method lacks reliability. Van der Lugt (2000) proposed distinguished the relationship between ideas in the design process by proposing three types of links: Supplement (S), Modification (M), and Tangential (T). The Supplement (S) link refers to minor improvements between adjacent ideas. The Modification (M) link refers to structural adjustments while maintaining existing ideas. The Tangential $(\mathrm{T})$ link characterizes two related but very different ideas. These two ideas suggest design solutions capable of achieving different functions. The more tangential links there are in a design process, the richer the design ideas' novelty. Furthermore, Cai et al. (2010) found that the distribution pattern of extended linkography can characterize the creativity of a design. The greater the number of design alternatives, the more creative the design solution.

Jansson and Smith (1991) used the metric "the number of designs which is highly similar to the example design" to quantify design fixation. However, highly similar concepts that rely too heavily on subjectivity lack reliability. Perttula and Sipilä (2007) calculated the Link Density Index (LDI) to quantify the genealogical linkages between examples and design solutions. A high LDI indicated that the designer falls into design fixation. Furthermore, in the extended linkingography, the linkage between two adjacent moves usually reflects the repetition of the previous move features by the latter one. This frequent repetition of the previous move features can be regarded as a sign of design fixation (Cai et al., 2010). These studies provide concrete methods to evaluate the creativity and degree of design fixation.

The above studies reported the effects of different types (Cai et al., 2010) and different levels of abstraction of analogical stimuli on designers (Casakin, 2004; Alipour, 2017). However, specific, single visual analogical stimuli on the effects of designers have not been reported. In addition, research has shown that analogical stimuli have significantly different effects on designers at different levels of expertise (Casakin, 2004). This leads to our research questions: Do specific analogy stimuli enhance or limit students' creativity? Do the effects of specific analogical stimuli differ for students with different levels of expertise? The aim of this study is to analyze the differences in the design performance of students at different design levels under the specific analogical stimuli by analyzing their sketches, protocol data, and linkography during design-by-analogy.

The study was carried out by testing three related hypotheses. Based on previous research findings, our first hypothesis is that during design-by-analogy, beginning students will focus on exploring the breadth of the design problem and have more lateral transformation (LT), and advanced students will focus on exploring the depth of design problem and have more vertical transformation (VT) (Hypothesis 1). In Van der Lugt's (2000) study, the high number of tangential links signified a process rich in novel combinations, and most tangential links were based on free association. Therefore, our second hypothesis is that free association analogical stimuli (nonspecific analogical stimuli) would increase the students' creativity during analogical design (Hypothesis 2). Jansson and Smith (1991) suggested that providing designers with design examples creates design fixation. These examples led designers to focus on existing design concepts and limit their ability to develop new ideas. In addition, idea generation consists of two cognitive processes: knowledge activation and idea production (Nijstad and Stroebe, 2006). Beginning students lack sufficient expertise to analyze and use the clues provided by the example in depth (Cai et al., 2010). Our third hypothesis is that specific analogical stimuli make the students fall into fixation, and it has a more pronounced effect on students in higher grades (Hypothesis 3 ).

\section{METHOD}

\subsection{Design task}

The design task is to design a China Railway Highspeed (CRH) locomotive using the design-byanalogy method. CRH locomotive is a common industrial product in the daily life of students at Tongji University. They have never designed this product before. This can ensure that the information the participants referred to was obtained from the materials provided for the experiment, rather than generating ideation relying on the previous design experience.

\subsection{Participants}

We recruited 12 participants. The beginning students' group has six undergraduate students (three first year students, three second year students, three females, three males, aged 18-21 years; average age 
19.67 years). The advanced students' group has six postgraduate students (two second year students, four third year students, three females, three males, aged 23-26 years; average age 24.83 years). All participants were industrial design students of Tongji University, and they all received a small honorarium for their participation.

\subsection{Materials}

To select the appropriate specific analogical source, we referred to a study on the analogy design of high-speed train locomotive (Lu et al., 2010). The research results showed that the bird body has good aerodynamic performance and is suitable as an analogical source for CRH locomotives. An eagle's beak is convex and round, and its head has a natural connection and transition. From hundreds of eagle pictures, we selected three eagles in different states as the source of analogy, as shown in Figure 1.
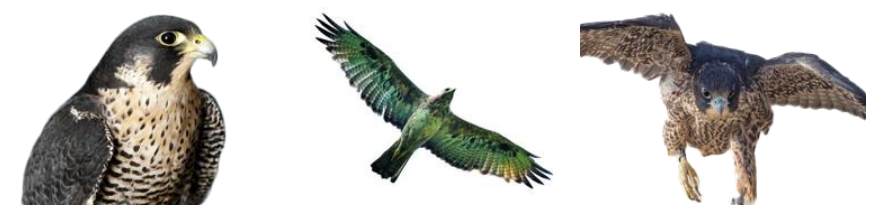

Figure 1. Analogical sources

\subsection{Procedure}

The advanced students were divided into two groups of three each: Group A and Group B. Beginning students were divided into two groups of three each: Group C and Group D. Before the formal experiment, the design-by-analogy method and process were explained in detail to the participants, as well as the differences in within-domain and between-domain analogical sources. The formal experiment was divided into four stages, as shown in Figure 2. At the first stage, the participants were informed of the design task and experimental procedure, and they were required to complete the design task using the design-by-analogy. The second stage is the thinking stage. The stage lasted for 10 min. Subjects selected analogy sources and extracted analogical features based on the given experimental conditions at this stage. The subjects in Groups B and D were provided with a visual display of eagle pictures as the specific analogical stimuli. In contrast, the subjects of Groups A and C were asked to use free association to select the between-domain analogical sources. Table 1 shows the grouping information of participants and experimental conditions. The third stage is the think-aloud stage, where the participants state the analogical sources they selected and their design ideas. We set this stage at $10 \mathrm{~min}$. In the fourth stage, participants were required to draw sketches and make an oral presentation simultaneously. This stage lasted for $30 \mathrm{~min}$.

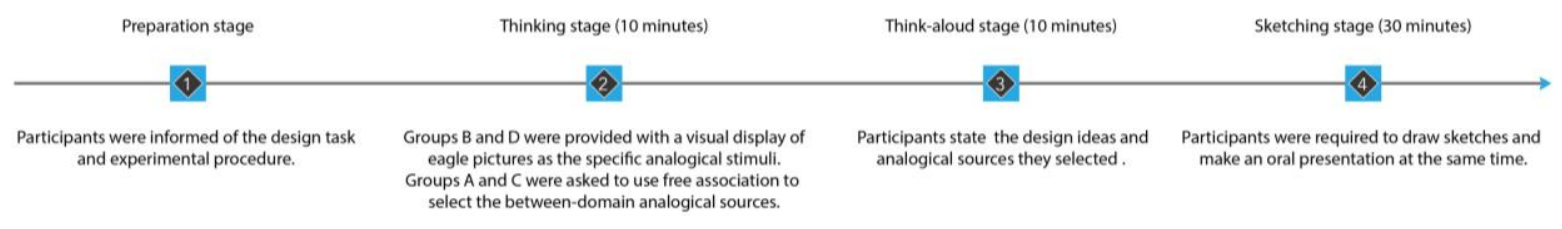

Figure 2. Experimental procedure

Table 1. The grouping of participants and the experimental conditions

\begin{tabular}{|c|c|c|c|c|}
\hline $\begin{array}{c}\text { Type of } \\
\text { analogy }\end{array}$ & $\begin{array}{c}\text { Advanced } \\
\text { students }\end{array}$ & $\begin{array}{c}\text { Beginning } \\
\text { students }\end{array}$ & Experimental conditions & Requirements \\
\hline $\begin{array}{c}\text { Nonspecific } \\
\text { analogy }\end{array}$ & Group A & Group C & $\begin{array}{c}\text { Participants in this group } \\
\text { needed to select the between- } \\
\text { domain analogical sources } \\
\text { based on experience and } \\
\text { common sense. }\end{array}$ & $\begin{array}{c}\text { Participants can select } \\
\text { analogical sources for } \\
\text { analogical designs by free } \\
\text { association. }\end{array}$ \\
\hline $\begin{array}{c}\text { Specific } \\
\text { analogy }\end{array}$ & Group B & Group D & $\begin{array}{c}\text { Participants in this group were } \\
\text { provided with three pictures of } \\
\text { eagles in different poses as } \\
\text { analogical sources. }\end{array}$ & $\begin{array}{c}\text { Participants were asked } \\
\text { to extract the features of } \\
\text { the provided eagles for } \\
\text { analogical design. }\end{array}$ \\
\hline
\end{tabular}




\section{RESULTS}

\subsection{Qualitative comparison of four Groups' design performance}

In general, Groups A and B proposed the least design alternatives. Group C used the largest number of analogical sources and generated the most design alternatives. Group D produced the fewest process sketches. The results are shown in Table 2.

Table 2. Number of design alternatives and process sketches created by participants

\begin{tabular}{|c|c|c|c|c|c|c|c|c|c|c|c|c|}
\hline $\begin{array}{c}\text { Experimental } \\
\text { conditions }\end{array}$ & \multicolumn{3}{|c|}{$\begin{array}{c}\text { Nonspecific } \\
\text { analogical stimuli, } \\
\text { Advanced students }\end{array}$} & \multicolumn{2}{c|}{$\begin{array}{c}\text { Specific analogical } \\
\text { stimuli, Advanced } \\
\text { students }\end{array}$} & \multicolumn{2}{c|}{$\begin{array}{c}\text { Nonspecific } \\
\text { analogical stimuli, } \\
\text { Beginning students }\end{array}$} & \multicolumn{3}{c|}{$\begin{array}{c}\text { Specific analogical } \\
\text { stimuli, Beginning } \\
\text { students }\end{array}$} \\
\hline Group & \multicolumn{3}{|c|}{ Group A } & \multicolumn{3}{c|}{ Group B } & \multicolumn{3}{c|}{ Group C } & \multicolumn{3}{c|}{ Group D } \\
\hline Subject & A1 & A2 & A 3 & B1 & B2 & B3 & C1 & C2 & C3 & D1 & D2 & D3 \\
\hline $\begin{array}{c}\text { Analogical } \\
\text { sources }\end{array}$ & 2 & 2 & 3 & 4 & 5 & 2 & 7 & 7 & 9 & 4 & 6 & 3 \\
\hline $\begin{array}{c}\text { Design } \\
\text { alternatives }\end{array}$ & 2 & 2 & 3 & 2 & 2 & 2 & 7 & 7 & 8 & 5 & 4 & 4 \\
\hline $\begin{array}{c}\text { Process } \\
\text { sketches }\end{array}$ & 13 & 9 & 10 & 9 & 10 & 11 & 8 & 9 & 9 & 8 & 7 & 7 \\
\hline
\end{tabular}

The participants used analogical sources, as shown in Table 3. The largest number of analogical sources were used in Group C. They considered more analogical sources similar in appearance to the $\mathrm{CRH}$ locomotive, such as bullets, fish, pyramids, missiles. Group A used the lowest number of analogical sources. They chose analogy sources with a sense of speed, such as sea creatures, birds, cheetahs. Group B used multiple eagle features to generate a design solution that contained a lot of detail, whereas Group D used one of the eagle's features to generate a design solution.

Table 3. Analogical sources used by each subject

\begin{tabular}{|c|c|c|c|c|c|c|}
\hline Subject & \multicolumn{6}{|c|}{ Analogical sources } \\
\hline A1 & Crocodile & Marine life & & & & \\
\hline A2 & $\begin{array}{l}\text { Bird's } \\
\text { wings }\end{array}$ & Dugong & & & & \\
\hline A3 & Bird & Dolphin & Cheetah & & & \\
\hline B1 & $\begin{array}{l}\text { Eagle's } \\
\text { beak, } \\
\text { nostrils }\end{array}$ & $\begin{array}{l}\text { Eagle's } \\
\text { beak, eyes, } \\
\text { and head }\end{array}$ & & & & \\
\hline B2 & $\begin{array}{c}\text { Eagle's eye, } \\
\text { beak }\end{array}$ & $\begin{array}{l}\text { Eagle's eyes, } \\
\text { beak, wings, } \\
\text { and nostrils }\end{array}$ & & & & \\
\hline B3 & $\begin{array}{l}\text { Eagle's } \\
\text { eyes, eagle } \\
\text { nostrils }\end{array}$ & $\begin{array}{c}\text { Eagle's } \\
\text { beak, eye, } \\
\text { and head }\end{array}$ & & & & \\
\hline $\mathrm{C} 1$ & Squid & Bullet & Pyramid & Knife & Fish & Rhinoceros horn \\
\hline $\mathrm{C} 2$ & Bird & Fighter & Snake & Shark & Sailfish & Missile \\
\hline $\mathrm{C} 3$ & Sea snake & Shark & Bullet & Bee & Dolphin & Bird \\
\hline D1 & $\begin{array}{c}\text { Eagle's } \\
\text { beak }\end{array}$ & $\begin{array}{c}\text { Eagle's } \\
\text { wings }\end{array}$ & $\begin{array}{c}\text { Eagle's } \\
\text { eyes }\end{array}$ & $\begin{array}{c}\text { Eagle's } \\
\text { claws }\end{array}$ & $\begin{array}{c}\text { Eagle's } \\
\text { head }\end{array}$ & \\
\hline $\mathrm{D} 2$ & $\begin{array}{l}\text { Eagle's } \\
\text { head }\end{array}$ & Eagle's beak & $\begin{array}{c}\text { Eagle's } \\
\text { wings }\end{array}$ & $\begin{array}{c}\text { Eagle's } \\
\text { claws }\end{array}$ & & \\
\hline D3 & Eagle's eyes & Eagle's beak & $\begin{array}{l}\text { Eagle's } \\
\text { wings }\end{array}$ & $\begin{array}{c}\text { Eagle's } \\
\text { beak }\end{array}$ & & \\
\hline
\end{tabular}

We conducted a qualitative analysis based on each participant's design performance by reviewing the protocol data and videos. In this study, we use the subject, the number of design solutions, and the number of process sketches to index the design sketches. For instance, S-A1-2-4 represents the fourth sketch of the second solution generated by Subject A1. 
Group A members used a small number of analogical sources and obtained the least design alternatives but generated the largest number of process sketches. For instance, Subject A1 (Figure 3) first selected crocodile as the analogical source, as crocodile and CRH locomotive have a similar shape. The second analogical source she selected was marine life. She believed that most marine creatures have streamlined heads, satisfying the aerodynamic design requirements of locomotives. The members in this group used the analogical source and the previous scheme to generate the following scheme, so the two adjacent schemes showed surface similarities.

"In the next project, I will sketch such a shape, which may be the same as the previous one, but I may change the above part, referring to the design of some cars."

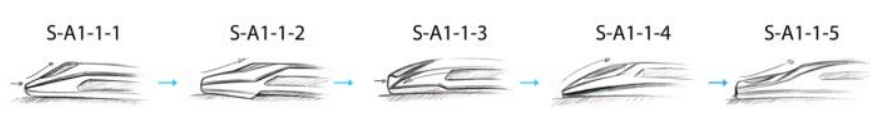

Figure 3. Part of the process sketches of Subject $A 1$

Group B generated a small number of design alternatives, and its members developed a large number of process sketches. Taking Subject B2 as an example, he flexibly selected the beak, eyes, wing, and nostrils of eagles mapping the fore-end, window, painting, and lights of the CRH locomotive. The subjects proposed a new scheme by improving the existing schemes (Figure 4).

"I am going to keep the shape of the beak in the next sketch. The shape of the eyes is too abstract. The current scheme looks too concrete. I will keep the front of the locomotive in such a shape, try to add some details. "

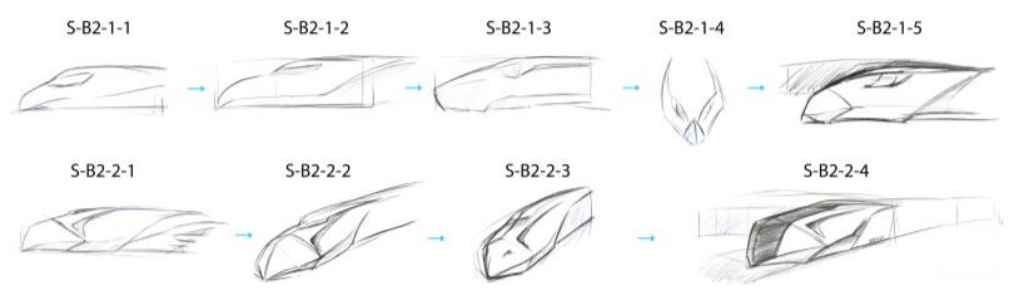

Figure 4. Part of the process sketches of Subject B2

Group $\mathrm{C}$ members used a variety of analogical sources, which generate the most design alternatives. Taking Subject $\mathrm{C} 1$ as an example, considering the streamlined modeling and aerodynamic performance of CRH locomotive, he selected analogical sources such as a bullet, a knife, and a bird. He also selected a squid, a rhinoceros horn, a pyramid, and other familiar objects in daily life as the analogical sources (Figure 5). Because of professional knowledge limitation, Group C members seldom made further designs on existing schemes like Group A. They put a lot of energy into exploring new analogical sources, so the degree of completion of the design scheme is low, and there is no apparent correlation between the schemes.

"Before the end of the experiment, my ideation dried up. It is difficult for me to think out a new idea."

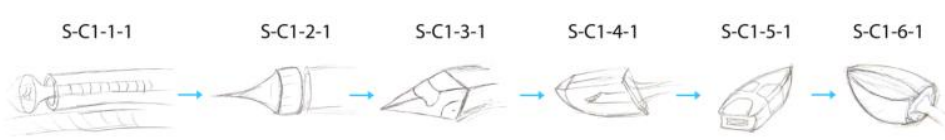

Figure 5. Part of the process sketches of Subject C1

Group D generated the least number of process sketches. They produced new design alternatives with new analogical sources. However, the specific analogical stimuli experimental condition made it more difficult for them to retrieve new analogical sources. Taking Subject D1 as an example, she used the eagle's beak, eyes, and wings as the analogical source for reasoning. Because he could not easily obtain new analogical sources, he tried to explore the depth of existing schemes (Figure 6).

"In addition to these, I can't think of a new scheme for the time being. I will draw another perspective of the scheme." 


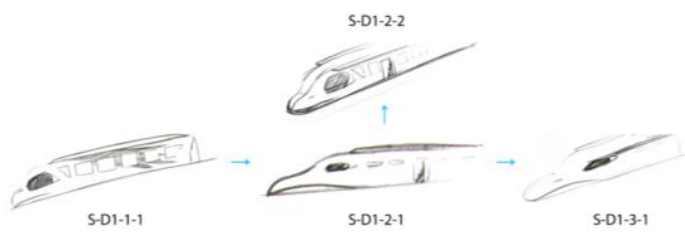

Figure 6. Part of the process sketches of Subject D1

\subsection{Extended linkography analysis}

We used a method known as extended linkography proposed by Cai et al. (2010). We defined the design objective (CRH locomotive) as the first step, which is represented by a hollow circle in the linkography. The process sketches generated by the participants in the design process are regarded as design units, and each process sketch is represented by a hollow circle. Besides, the connections between design steps are represented by solid points. These movements move in both horizontal and vertical directions. The movements in the horizontal axis represent design alternatives (LLT), and the movements in the vertical axis represent process sketches (LVT). The design unit in the horizontal direction represents an idea that is different from the former idea, or it is a design alternative. In the vertical direction, the latter idea is a small and auxiliary change of the former idea. Taking Subject A1 as an example (Figure 7), she sketched two design alternatives and twelve process sketches. The first design alternative has six sketches, and the second design alternative also has six sketches.

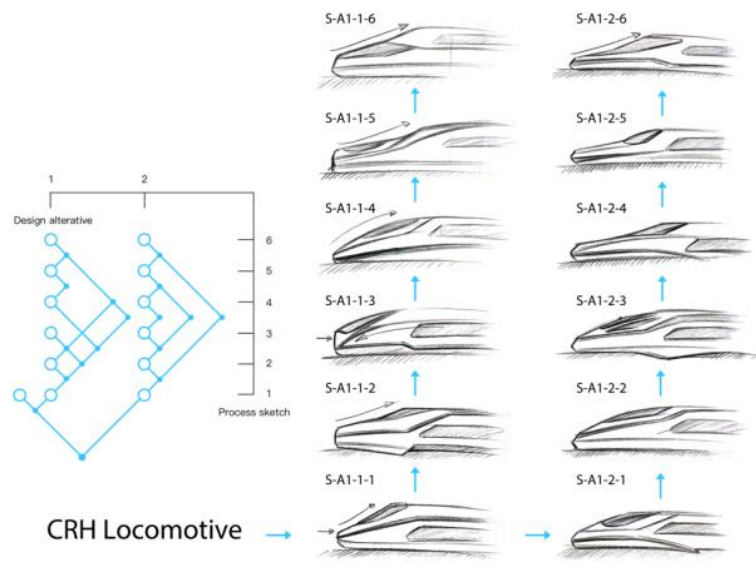

Figure 7. Extended linkography of Subject A1

Figure 8 shows the linkography generated by the students at different design levels by using analogical stimuli and nonspecific analogical stimuli. Hypothesis 1 was fully confirmed. We found that the advanced students had more LVT, reflecting an exploration of design problem depth. Beginning students had more LLT and proposed more design alternatives. It reflects an exploration of design problem breadth. This result is consistent with Cai et al.'s (2010) view that experienced designers are able to design in-depth based on the clues provided by the sketches. In contrast, inexperienced designers lack sufficient domain knowledge to explore the depth of the design problem.

The results obtained from the experiment partially confirmed Hypothesis 2. The nonspecific analogical stimuli enhanced the creativity of beginning students as they proposed more design alternatives than the beginning students in the specific analogical stimuli group. We postulate that this point is related to the fact that the beginning students in the nonspecific analogical stimuli group had the flexibility to use a broader range of analogical sources, such as sailfish, sharks, cheetahs, and birds, whereas the beginning students in the specific analogical stimuli group were limited to use eagles' eyes, beak, wings, and other eagle-related objects as analogical sources. However, this is not obvious for advanced students. They preferred to add a lot of design solution details. This is consistent with the findings of Cao et al. (2018). The beginning students produced more design solutions that contained fewer details, and advanced students produced fewer design solutions that contained more details.

Hypothesis 3 was fully confirmed. The specific analogical stimuli groups have more recurrence of elements from previous moves than the nonspecific stimuli group in extended linkography. This means specific analogical stimulus attracts students into a fixation. We found subtle differences 
through the analysis of the sketches. With the specific analogical stimuli, advanced students' design solutions repeated features of the previous solution more frequently than those of beginning students. This suggests that the specific analogical stimuli lead the advanced students into a stronger design fixation. It is in line with the protocol data of the advanced students. "I'm going to keep the shape of the beak in the next sketch." In contrast, the beginning students were more inclined to use new analogical sources to generate more solutions.
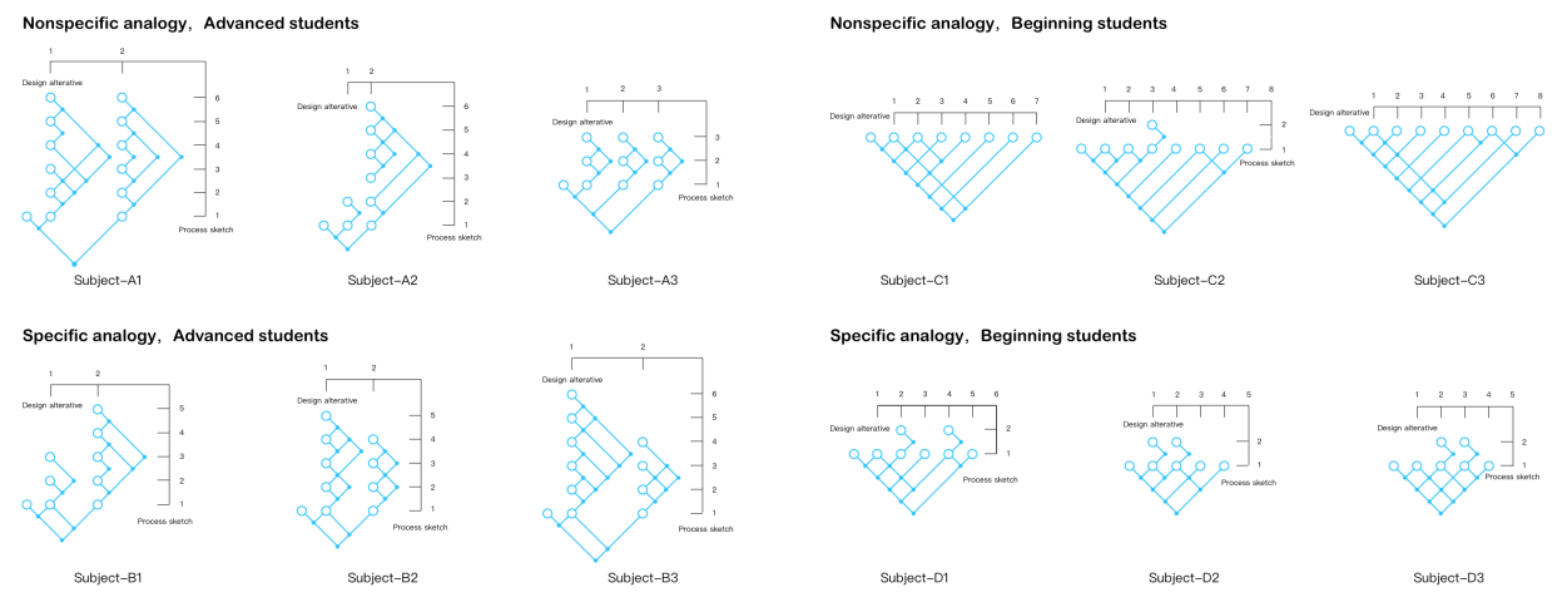

Figure 8. Extended linkography of all participants

\section{CONCLUSION}

This study analyzed the differences in the effects of specific and nonspecific analogical stimuli on students at different design levels using protocol data and extended linkography. Based on these results, the following conclusions can be drawn: (1) Advanced students tend to explore the depth of the design problem, while beginning students focus on exploring the breadth of the design problem. (2) Nonspecific analogous stimuli enhance the creativity of beginning students. However, its impact on advanced students is less pronounced. (3) Specific analogical stimuli produce apparent fixation in advanced students, and it has a more pronounced effect on advanced students.

Besides, obvious differences were observed between advanced and beginning students in selecting analogical sources. Novices do not have the ability to explore the scheme in-depth, and they prefer to choose the analogical source they are familiar with in daily life based on experience, whereas the advanced students would like to choose fewer sources of analogy, and they are more inclined to use analogical sources to improve and strengthen the existing schemes.

Because this study is a small sample study, these findings need to be further explored. However, the results of qualitative analysis and quantitative analysis are consistent, indicating that extended linkography could be used in the design-by-analogy context. In our study, designers with rich industrial design experience were not included. After all, both undergraduate and graduate students of industrial design lack professional design experience of CRH locomotives, and the creativity and design fixation generated by specific analogy stimuli for these design experts may be different from the former two. In the future, we will invite professional designers to explore the effect of specific analogical stimuli on their design performance.

\section{ACKNOWLEDGMENTS}

This research is based upon work supported by the National Science Foundation of China under Grant No. 51205059, No. 61303037, the Major Consulting Projects of Chinese Academy of Engineering under Grant No. 2013ZD15, the Excellent Youth Scholars Foundation of Southeast University under Grant No. 3202004202, the Sichuan Education Department Humanities and Social Sciences Key Research Base Industrial Design Industry Research Centre Project under Grant No. GYSJ17-019. 


\section{REFERENCES}

Alipour, L. et al. (2017), “The impact of designers' goals on design-by-analogy”, Design Studies, Vol. 51, pp. 1-24. https://doi.org/10.1016/j.destud.2017.04.001.

Al-Obaidi, Y. A. and Pitts, G. (1995), "Using an analogies approach to the selection of bought-in components", Journal of Engineering Design, Vol. 6 No. 2, pp. 107-123. http://dx.doi.org/10.1080/09544829508907907.

Appleton, E. A. and Short, T. D. (2008), "New product development 'according to Hoyle': part 1-the analogy", Journal of Engineering Design, Vol. 19 No. 3, pp. 285-298. http://dx.doi.org/10.1080/09544820701402880.

Blanchette I. and Dunbar K. (2000), "How analogies are generated: The roles of structural and superficial similarity", Memory and Cognition, Vol. 28 No. 1, pp.108-124. http://dx.doi.org/10.3758/bf03211580.

Clement, C. A., and Gentner, D. (1991), "Systematicity as a selection constraint in analogical mapping", Cognitive Science, Vol.15 No.1, pp.89-132. http://dx.doi.org/10.1207/s15516709cog1501_3.

Cai, H., Do, E. Y.-L. and Zimring, C. M. (2010), "Extended linkography and distance graph in design evaluation: An empirical study of the dual effects of inspiration sources in creative design", Design Studies, Vol. 31 No. 2, pp.146-168. http://dx.doi.org/10.1016/j.destud.2009.12.003.

Cao, J. et al. (2018), "Differences between beginning and advanced design students in analogical reasoning during idea generation: evidence from eye movements", Cognition, Technology and Work, Vol. 20 No. 3 , pp.505-520. http://dx.doi.org/10.1007/s10111-018-0477-z.

Casakin, H. and Goldschmidt, G. (1999), "Expertise and the use of visual analogy: implications for design education”, Design Studies, Vol. 2 No. 2, pp.153-175. http://dx.doi.org/10.1016/s0142-694x(98)00032-5.

Casakin, H. and Goldschmidt, G. (2000), "Reasoning by visual analogy in design problem-solving: The role of guidance”, Environment and Planning B: Planning and Design, Vol. 27 No. 1, pp.105-119. http://dx.doi.org/10.1068/b2565.

Casakin, H. (2004), "Visual analogy as a cognitive strategy in the design process. Expert versus novice performance", Journal of Design Research, Vol. 4 No. 2, pp.197-217. http://dx.doi.org/10.1504/jdr.2004.009846.

Chan, J. et al. (2011), "On the benefits and pitfalls of analogies for innovative design: Ideation performance based on analogical distance, commonness, and modality of examples”, Journal of Mechanical Design, Vol. 133 No. 8, p.081004. http://dx.doi.org/10.1115/1.4004396.

Chan, J. \& Schunn, C., (2014), "The impact of analogies on creative concept generation: Lessons from an in vivo study in engineering design", Cognitive Science, Vol. 39 No. 1, pp.126-155. http://dx.doi.org/10.1111/cogs.12127.

Chou, A. and Shu, L. H. (2015), "Using analogies to explain versus inspire concepts", Artificial Intelligence for Engineering Design, Analysis and Manufacturing, Vol. 29 No. 2, pp.135-146. http://dx.doi.org/10.1017/s0890060415000025.

Christensen, B. T. and Schunn, C. D. (2007), "The relationship of analogical distance to analogical function and preinventive structure: The case of engineering design", Memory and Cognition, Vol. 35 No. 1, pp.29-38. http://dx.doi.org/10.3758/bf03195939.

Cardoso, C. and Badke-Schaub, P. (2009), "Idea fixation in design: the influence of pictures and words", International Conference on Research into Design (ICoRD’ 09), Bangalore, January 2009, pp.51-58.

De Bono, E. (1990). Lateral Thinking, Penguin Books, London.

El-Khouly, T. and Penn, A. (2014), "On an integrated analytical approach to describe quality design process in light of deterministic information theory", In: Gero, J. S. (Ed.), Design Computing and Cognition '12, Springer, Berlin, pp. 451-470. http://dx.doi.org/10.1007/978-94-017-9112-0_25.

$\mathrm{Fu}, \mathrm{K}$. et al. (2014), "Bio-Inspired design: An overview investigating open questions from the broader field of design-by-analogy", Journal of Mechanical Design, Vol. 136 No. 11, p.111102. http://dx.doi.org/10.1115/1.4028289.

Gentner, D. (1988). "Structure-Mapping: A theoretical framework for analogy". Readings in Cognitive Science, Vol. 22 No.3, pp.303-310. http://dx.doi.org/10.1016/b978-1-4832-1446-7.50026-1.

Goldschmidt G. (1990), "Linkography: Assessing design productivity”, In: Trappl, R. (Ed.), Cybernetics and System '90, World Scientific, Singapore, pp.291-298.

Goldschmidt, G. (2001), "Visual analogy: A strategy for design reasoning and learning”, In: C. Eastman, C., Mccracken, M., Newsletter, W. (Ed.), Design Knowing and Learning: Cognition in Design Education. Elsevier, New York, pp. 199-220. https://doi.org/10.1016/B978-008043868-9/50009-7.

Goldschmidt, G., and Smolkov, M. (2006), "Variances in the impact of visual stimuli on design problems solving performance", Design Studies, Vol. 27 No. 5, pp.549-569. http://dx.doi.org/10.1016/j.destud.2006.01.002.

Helms, M. and Goel, A. K. (2014), "The four-box method: Problem formulation and analogy evaluation in biologically inspired design”, Journal of Mechanical Design, Vol. 136 No. 11, p. 111106.

http://dx.doi.org/10.1115/1.4028172. 
Howard, T., Culley, S., Dekoninck, E., (2011), "Reuse of ideas and concepts for creative stimuli in engineering design”, Journal of Engineering Design, Vol. 22 No. 8, pp.565-581. http://dx.doi.org/10.1080/09544821003598573.

Jansson, D., and Smith, S. (1991), "Design fixation", Design Studies, Vol. 12 No. 1, pp.3-11. http://dx.doi.org/10.1016/0142-694x(91)90003-f.

Kan, J. W. T. and Gero, J. S. (2005), "Can entropy indicate the richness of idea generation in team designing? “, Proceedings of the 10th International Conference on Computer-Aided Architectural Design Research in Asia (CAADRIA 2005), New Delhi (India), 28-30 April 2005, pp. 451-457.

Kan, J. W. T. and Gero, J. S. (2008), "Acquiring information from linkography in protocol studies of designing", Design Studies, Vol. 29 No. 4, pp.315-337. http://dx.doi.org/10.1016/j.destud.2008.03.001.

Keshwani, S. and Chakrabarti, A. (2016), "Influence of analogical domains and comprehensiveness in explanation of analogy on the novelty of designs", Research in Engineering Design, Vol. 28 No. 3, pp.381-410. http://dx.doi.org/10.1007/s00163-016-0246-z.

Lu J.N., Xu B.C., Ding L. (2017), "Three different kinds of bio-inspired design of high-speed train head", Packaging Engineering, Vol. 38 No. 2, pp.26-30.

Moreno, D. P. et al. (2016), "Overcoming design fixation: Design by analogy studies and nonintuitive findings", Artificial Intelligence for Engineering Design, Analysis and Manufacturing, Vol. 30 No. 2, pp.185-199. http://dx.doi.org/10.1017/s0890060416000068.

Ngo, P., Turner, C. J. and Linsey, J. S. (2014), "Identifying trends in analogy usage for innovation: A crosssectional product study”, Journal of Mechanical Design, Vol. 136 No. 11, p.111109. http://dx.doi.org/10.1115/1.4028100.

Nijstad, B., and Stroebe, W. (2006), "How the group affects the mind: a cognitive model of idea generation in groups", Personality and Social Psychology Review, Vol. 10 No. 3, pp.186-213. http://dx.doi.org/10.1207/s15327957pspr1003_1.

O’Rourke, J. M. and Seepersad, C. C. (2015), “Toward a methodology for systematically generating energy-and materials-efficient concepts using biological analogies”, Journal of Mechanical Design, Vol. 137 No. 9, p. 091101. http://dx.doi.org/10.1115/1.4030877.

Perttula, M. and Sipilä, P. (2007), “The idea exposure paradigm in design idea generation”, Journal of Engineering Design, Vol. 18 No.1, pp.93-102. http://dx.doi.org/10.1080/09544820600679679.

Purcell, A. T., and Gero, J. S. (1996), "Design and other types of fixation”, Design Studies, Vol. 17 No.4, pp.363-383. http://dx.doi.org/10.1016/s0142-694x(96)00023-3.

Paletz, S.B.F., Schunn, C.D. \& Kim, K.H. (2013), "The interplay of conflict and analogy in multidisciplinary teams", Cognition, Vol. 126 No.1, pp.1-19. https://doi.org/10.1016/j.cognition.2012.07.020.

Van der Lugt, R. (2000), "Developing a graphic tool for creative problem solving in design groups", Design Studies, Vol. 21 No. 5, pp.505-522. http://dx.doi.org/10.1016/s0142-694x(00)00021-1. 